TITLE:

\title{
Multi-modal 19F NMR probe using perfluorinated cubic silsesquioxane-coated silica nanoparticles for monitoring enzymatic activity.
}

\author{
AUTHOR(S): \\ Tanaka, Kazuo; Kitamura, Narufumi; Naka, \\ Kensuke; Chujo, Yoshiki
}

\section{CITATION:}

Tanaka, Kazuo ...[et al]. Multi-modal 19F NMR probe using perfluorinated cubic silsesquioxane-coated silica nanoparticles for monitoring enzymatic activity.. Chemical communications (Cambridge, England) 2008, 2008(46): 6176-6178

\section{ISSUE DATE:}

2008-12-14

URL:

http://hdl.handle.net/2433/123366

\section{RIGHT:}

Chem. Commun., 2008, pp.6176-6178 - Reproduced by permission of The Royal Society of Chemistry (RSC); この論文は出版社版でありません。引用の際には出版社版をご確認ご 利用ください。; This is not the published version. Please cite only the published version. 


\title{
Multi-Modal ${ }^{19}$ F NMR Probe Using Perfluorinated Cubic Silsesquioxane-Coated Silica Nanoparticles for Monitoring Enzymatic Activity
}

\author{
Kazuo Tanaka, ${ }^{a}$ Narufumi Kitamura, ${ }^{a}$ Kensuke Naka, ${ }^{b}$ and Yoshiki Chujo ${ }^{* a}$
}

Received (in XXX, XXX) 1st January 2007, Accepted 1st January 2007

First published on the web 1st January 2007

DOI: 10.1039/b000000x

\begin{abstract}
${ }_{5}$ The manuscript describes the establishment of the ${ }^{19} \mathrm{~F}$ NMR signal regulation and the application of this strategy to develop the multi-modal ${ }^{19}$ F NMR probe for monitoring enzymatic activity using nanoparticles as a signal regulator. Water-soluble perfluorinated cubic silsesquioxane was synthesized and 10 immobilized onto the silica nanoparticles for suppressing the signals. ${ }^{19} \mathrm{~F}$ NMR signals of the probes were recovered by releasing from nanoparticles.
\end{abstract}

Magnetic resonance imaging (MRI) is one of the powerful diagnostic tools as a noninvasive diagnosis method, and 15 through the use of the contrast agents, site- and time-selective information can be received. ${ }^{19} \mathrm{~F}$ MRI using fluorinated compounds as the contrast agents has recently gathered attentions because less existence of endogenous fluorine atom gives the high signal to noise ratio in the images. ${ }^{1}$ In addition, 20 several groups have reported functional ${ }^{19} \mathrm{~F}$ NMR probes which can detect the enzymatic activity or the environmental alteration by changing of their signal heights or chemical shifts. ${ }^{2}$ Furthermore, fusion of multiple information has been increasingly required for improving the diagnosis accuracy, 25 thus molecular imaging probes for next generation should equip the multimodality. ${ }^{3}$

The accumulation of an equal fluorine group is essential for improving the sensitivity of the ${ }^{19} \mathrm{~F}$ NMR signals, however, perfluorinated compounds would exhibit extremely poor 30 water-solubility. One way to solve these problems is to use cubic octameric polyhedral oligomeric silsesquioxanes (POSS) as a scaffold for the accumulation of fluorine atoms. POSS are highly-water-soluble nanoblocks, and it has been reported that POSS could form the compact structure 35 compared to the same generation of poly(amido)amine dendrimers. ${ }^{4}$ These characteristics can be beneficial for the accumulation of the probe molecules with high density to improve sensitivity.

Herein, we report the regulation system of ${ }^{19} \mathrm{~F}$ NMR signals 40 for monitoring bioreactions based on the water-soluble perfluorinated POSS-coated silica nanoparticles (NPs). The enzymatic reaction can be monitored by the enhancement of ${ }^{19} \mathrm{~F}$ NMR signals. In addition, we develop the multi-modal probe with dual detection of fluorescence and ${ }^{19} \mathrm{~F}$ NMR. This
45 is the first example that the NPs can be used for the NMR signal regulation.

The chemical structures and synthesis of the water-soluble perfluorinated POSS (F-POSS) using octaammonium POSS $\mathbf{1}^{5}$ as a starting material are shown in Scheme 1. F-POSS has 50 trifluoroacetyl groups as the ${ }^{19} \mathrm{~F}$ NMR signal moiety. The major product was identified with modified POSS containing $\mathrm{POSS}_{-\mathrm{TFA}_{4}}$ from MALDI-TOF-MS measurements. The solubility of F-POSS in PBS $(\mathrm{pH}=7.5)$ at $25^{\circ} \mathrm{C}$ was at least $10 \mathrm{mM}$ (120 mM F atom concentration), and the significant 55 peak broadening following the decrease of sensitivity was not observed by adding to $\mathrm{BSA}(1 \mathrm{mg} / \mathrm{mL})$ or the $\mathrm{pH}$ altering between $\mathrm{pH} 5$ to 9 . In addition, the degradation of F-POSS was not observed after $24 \mathrm{~h}$ incubation at $37{ }^{\circ} \mathrm{C}$ at $\mathrm{pH} 7.0$ in the presence of proteinase $\mathrm{K}$. The detection limit was ${ }_{60}$ determined to be $10 \mu \mathrm{M}$ using ${ }^{19} \mathrm{~F}$ NMR spectrometer with a $20 \mathrm{~mm}$ surface coil at $9.4 \mathrm{~T}$. These results suggest that $\mathrm{F}$ POSS could provide clear ${ }^{19} \mathrm{~F}$ NMR signals without loss of sensitivity caused by unexpected interactions in vivo.

Scheme 1
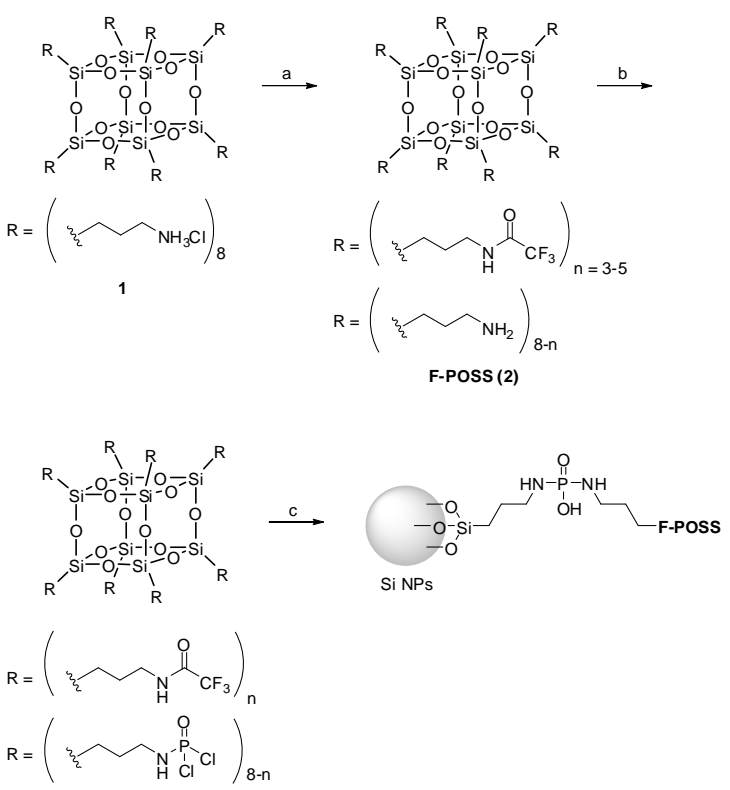

${ }^{a}$ Reagents: (a) ethyl trifluoroacetate, triethylamine, methanol, $83 \%$; (b) phosphorus oxytrichloride, triethylamine, chloroform; (c) amino-modified silica nanoparticles, chloroform. 
Scheme 2
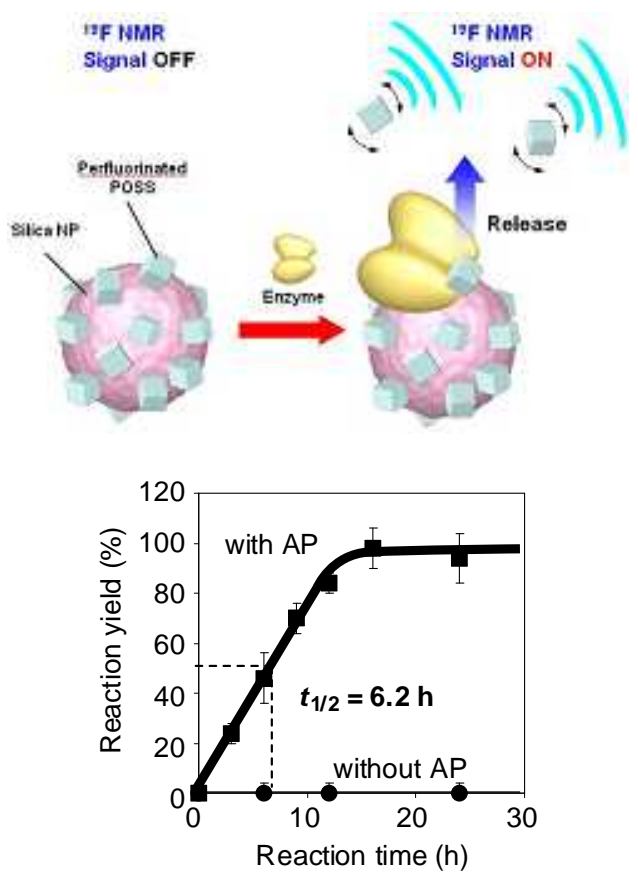

Fig. 1 Time-course of the enzymatic reaction. F-POSS-coated silica NPs $(1.5 \mathrm{mg})$ were incubated in $500 \mu \mathrm{L}$ of the reaction solutions containing $\mathrm{AP}(5 \mathrm{U})$ (square dots) and non-containing AP (circular dots) in $50 \mathrm{mM}$ sodium phosphate, $25 \mathrm{mM}$ Tris- $\mathrm{HCl}$, and $0.05 \mathrm{mM}$ EDTA $(\mathrm{pH}=7.0)$ at $37{ }^{\circ} \mathrm{C}$. The reaction yields were monitored with ${ }^{19} \mathrm{~F}$ NMR and calculated by the fitting on the standard curve. a)

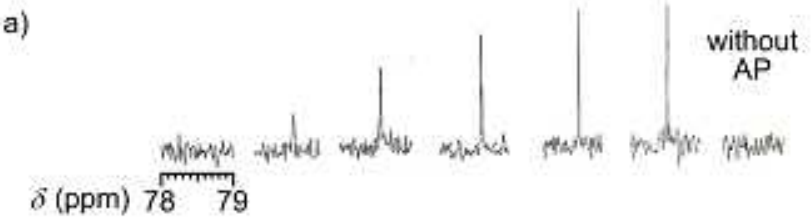

Fig. 2 (a) ${ }^{19} \mathrm{~F}$ NMR spectra of F-POSS-coated silica NPs in diameter of $150 \mathrm{~nm}$ containing fluorescein-5(6)-carboxylic acid in enzymatic hydrolysis with AP. (b) The fluorescence image was taken using a transilluminator $(365 \mathrm{~nm}$ ) through a 480 -nm long pass emission filter.

Scheme 2 illustrates the strategy for the regulation of ${ }^{19} \mathrm{~F}$ NMR signals. In a solid state, the sensitivity of NMR signal was decreased by the acceleration of transverse relaxation time and the anisotropy of the spin toward the external 5 magnetic fields. On silica NPs, the molecular rotation of the perfluorinated POSS should be highly restricted, and the NMR signals from the probe can be decreased. ${ }^{2 b}$ After releasing the probe triggered by an enzymatic reaction, the NMR signals are recovered. Therefore, the enzyme activity 10 can be detected by the enhancement of the signal intensity of

\section{${ }^{19}$ F NMR.}

NPs in the range of $20 \mathrm{~nm}$ to $400 \mathrm{~nm}$ in diameter show tumor-selective integration known as the enhanced permeability and retention (EPR) effect. ${ }^{6}$ In addition, the 15 silica NPs can be attached with the fluorophores, and these fluorescent NPs displayed good feasibility for in vivo imaging because of photo-stability and less toxicity. ${ }^{7}$ We prepared amino-coated silica NPs averaging $150 \mathrm{~nm}$ and $280 \mathrm{~nm}$ in diameter containing or non-containing the fluorophores with 20 the Stöber method. ${ }^{8}$ Amino groups on F-POSS were covalently linked to the amino groups on the silica NPs via the phosphordiamidate linker which can be cleaved by the enzymatic digestion of alkaline phosphatase (AP). ${ }^{9}$ A class of AP is generally existing in the cell cytoplasm or surface in the 25 whole body, and they can digest phosphodiester analog without specificity. ${ }^{9}$ Thus, in combination with the EPR effect, the monitoring system of the AP activity could be a new method for the early cancer diagnosis.

The reaction mixture containing F-POSS and triethylamine 30 in chloroform was added to phosphorus oxytrichloride at room temperature, and subsequently the amino-coated silica NPs were suspended in the mixture in one pot. The reaction was monitored by ninhydrin reagents for checking the consumption of the amino groups on the NPs. After 35 purification with centrifuges and drying, we confirmed from dynamic light scattering that unexpected aggregation of the modified NPs was not formed after modification with F-POSS, and the diameters of synthetic NPs were determined from the TEM images. ${ }^{10}$ From the fitting to the standard curve on ${ }^{19} \mathrm{~F}$ 40 NMR signal intensity, it was estimated that $100( \pm 20) \mathrm{nmol} /$ $\mathrm{mg}$ of F-POSS was immobilized onto the silica NPs. Undesired decomposition of the probe less occurred by the proteinase $\mathrm{K}$ treatment or the $\mathrm{pH}$ alteration between $\mathrm{pH} 5$ to 9 .

The reactivity of the F-POSS-coated silica NPs with AP 45 was investigated. Initially, the modified NPs averaging 150 $\mathrm{nm}$ in diameter were used. The reaction mixtures containing 3 $\mathrm{mg} / \mathrm{mL}$ of the modified NPs (300 $\mu \mathrm{M}$ F-POSS) and AP in 50 $\mathrm{mM}$ sodium phosphate and $100 \mathrm{mM}$ Tris- $\mathrm{HCl}$ buffer $(\mathrm{pH}=$ 7.0) were incubated at $37{ }^{\circ} \mathrm{C}$, and ${ }^{19} \mathrm{~F}$ NMR signals of the 50 mixture were monitored (Figure 1). The signal was linearly increasing and stopped after $12 \mathrm{~h}$ incubation $\left(t_{50}=6.2 \mathrm{~h}\right)$. In the absence of the enzyme, NMR signal was hardly detected even after $24 \mathrm{~h}$ incubation. In the case of $280 \mathrm{~nm}$ diameter of the NPs, the rate of the signal intensity was similar extent as 55 those of $150 \mathrm{~nm}\left(t_{50}=6.0 \mathrm{~h}\right) .{ }^{11}$ These results indicate that the

${ }^{19} \mathrm{~F}$ NMR signals could be obtained independently on the size of NPs. The time-scale of these reactions might be adequate to obtain the EPR effect due to the prevention from non-specific digestion of the NPs during the transportation.

${ }_{60}$ We demonstrated the multimodal detection with fluorescence and ${ }^{19} \mathrm{~F}$ NMR for the enzymatic activity. Time course of ${ }^{19} \mathrm{~F}$ NMR signals of the F-POSS-modified silica NPs containing fluorescein-5(6)-carboxylic acid is shown in Figure 2a. ${ }^{12}$ AP activity induced a signal enhancement after $3 \mathrm{~h}$ 65 incubation, and the signal intensity was saturated after $12 \mathrm{~h}$ incubation. This result corresponds with the data shown in Figure 1. Fluorescence emission from fluorescent silica NPs was constantly observed during reactions without 
photobleaching (Figure 2b). These data suggest that the fluorescence can be used as a reference to zero for scanning the distribution of the probes and estimating the absolute intensity of ${ }^{19} \mathrm{~F}$ NMR signal. ${ }^{13}$ Although the sensitivity of the ${ }_{5}$ probe for acquiring clear signals in the ${ }^{19} \mathrm{~F}$ NMR spectra was lower than that for the fluorescence image, our system could have a possibility to improve sensitivity by employing POSScore dendrimers for incorporating the larger number of fluorine atoms into the probe.

${ }_{10}$ In conclusion, we describe here a novel ${ }^{19} \mathrm{~F}$ NMR probes using perfluorinated POSS, and the enzymatic activity can be monitored by the enhancement of their ${ }^{19} \mathrm{~F}$ NMR signals. Using the fluorescent NPs, the dual detection with ${ }^{19} \mathrm{~F}$ NMR and fluorescence was accomplished potentially for the 15 simultaneous monitoring of the enzymatic activity and the biodistribution. Though there reminds room to optimize reactivity or to evaluate the toxicity and the biodistiribution in living animals, our system could be applied to the sensing of not only $\mathrm{pH}$ via hydrolysis but also other kinds of enzymes

20 such as nucleases and proteases by the modification with the linker. In addition, a detection modality can be added by the modulation of the material of NPs. It is expected that this strategy is helpful for designing new generation of molecular imaging probes.

25 This study was conducted as a part of the project, "R\&D of Molecular Imaging Equipment for Malignant Tumor Therapy Support," supported by NEDO (New Energy and Industrial Technology Development Organization). We thank Prof. Y. Tsuji and Dr. T. Fujiwara for the measurement of ${ }^{19} \mathrm{~F}$ NMR. ${ }_{30}$ We thank Prof. M. Nagao and Ms. M. Chujo for the MTT assay. We thank Prof. I. Hamachi and Mr. S. Fujishima for taking the fluorescence images.

\section{Notes and references}

\author{
${ }^{a}$ Department of Polymer Chemistry \\ 35 Graduate School of Engineering, Kyoto University \\ Katsura, Nishikyo-ku, Kyoto 615-8510 (Japan) \\ Fax: (+81) 75-383-2605 \\ E-mail: chujo@chujo.synchem.kyoto-u.ac.jp \\ ${ }^{b}$ Department of Chemistry and Materials Technology \\ 40 Graduate School of Science and Technology \\ Kyoto Institute of Technology \\ Sakyo-ku, Kyoto 606-8585 (Japan) \\ $\dagger$ Electronic Supplementary Information (ESI) available: [details of any \\ supplementary information available should be included here]. See
} 45 DOI: $10.1039 / \mathrm{b} 000000 \mathrm{x}$

1 (a) U. Zimmermann, U. Nöth, P. Gröhn, A. Jork, K. Ulrichs, J. Lutz, A. Haase, Artif. Cells Blood Substit. Immobil. Biotechnol., 2000, 28, 129; (b) J. Yu, V. D. Kodibagkar, W. Cui, R. P. Mason, Curr. Med. Chem., 2005, 12, 819; (c) M. Higuchi, N. Iwata, Y. Matsuba, K. Sato,

$50 \quad$ K. Sasamoto, T. C. Saido, Nat. Neurosci., 2005, 8, 527; (d) E. T. Ahrens, R. Flores, H. Y. Xu, P. A. Morel, Nat. Biotechnol., 2005, 23, 983; (e) J. Maki, C. Masuda, S. Morikawa, M. Morita, T. Inubushi, Y. Matsusue, H. Taguchi, I. Tooyama, Biomaterials 2007, 28, 434; (f) A. M. Morawski, P. M. Winter, X. Yu, R. W. Fuhrhop, M. J. Scott, F.

55 Hockett, J. D. Robertson, P. J. Gaffney, G. M. Lanza, S. A. Wickline, Magn. Reson. Med., 2004, 52, 1255.

2 (a) S. Mizukami, R. Takikawa, F. Sugihara, Y. Hori, H. Tochio, M. Waelchli, M. Shirakawa, K. Kikuchi, J. Am. Chem. Soc., 2008, 130, 794; (b) M. Oishi, S. Sumitani, Y. Nagasaki, Bioconjug. Chem., 2007, 18, 1379; (c) W. Cui, P. Otten, Y. Li, K. S. Koeneman, J. Yu, R. P. Mason, Magn. Reson. Med., 2004, 51, 616.
3 (a) R. Weissleder, M. J. Pittet, Nature, 2008, 452, 580; (b) J. M. Janjic, M. Srinivas, D. K. K. Kadayakkara, E. T. Ahrens, J. Am. Chem. Soc., 2008, 130, 2832; (c) M. Xia, V. D. Kodibagkar, H. Liu,

65 R. P. Mason, Phys. Med. Biol., 2006, 51, 45; (d) Y. Hattori, T. Asano, Y. Niki, H. Kondoh, N. Kirihata, Y. Yamaguchi, T. Wakamiya, Bioorg. Med. Chem., 2006, 14, 3258.

4 (a) R. M. Laine, J. Choi, I. Lee, Adv. Mater., 2001, 13, 800; (b) X. Wang, K. Naka, H. Itoh, Y. Chujo, Chem. Lett., 2004, 33, 216.

705 (a) M.-C. Gravel, R. M. Laine, Am. Chem. Soc. Polym. Prepr., 1997, 38, 155; (b) F. J. Feher, K. D. Wyndham, Chem. Commun., 1998, 323; (c) M.-C. Gravel, C. Zhang, M. Dinderman, R. M. Laine, Appl. Organometal. Chem., 1999, 13, 329.

6 (a) G. Kong, R. D. Braun, M. W. Dewhirst, Cancer Res., 2000, 60, 75 4440; (b) O. Ishida, K. Maruyama, K. Sasaki, M. Iwatsuru, Int. J. Pharm., 1999, 190, 49; (c) D. C. Litzinger, A. M. Buiting, N. van Rooijen, L. Huang, Biochim. Biophys. Acta, 1994, 1190, 99; (d) F. Yuan, M. Leunig, S. K. Huang, D. A. Berk, D. Papahadjopoulos, R. K. Jain, Cancer Res., 1994, 54, 3352; (e) S. K. Hobbs, W. L. Monsky, 80 F. Yuan, W. G. Roberts, L. Griffith, V. P. Torchilin, R. K. Jain, Proc. Natl Acad. Sci. USA, 1998, 95, 4607; (f) H. Maeda, Adv. Enzyme Regul., 2001, 41, 189; (g) H. Maeda, J. Fang, T. Inutsuka, Y. Kitamoto, Int. Immunopharmacol., 2003, 3, 319.

7 (a) A. Burns, H. Ow, U. Wiesner, Chem. Soc. Rev., 2006, 35, 1028 85 (b) S. Santra, D. Dutta, G. A. Walter, B. M. Moudgil, Technol. Cancer Res. Treat., 2005, 4, 593; (c) N. L. Rosi, C. A. Mirkin, Chem. Rev., 2005, 105, 1547; (d) L. Wang, W. Tan, Nano Lett., 2006, 6, 84; (e) E. E. Graves, R. Weissleder, V. Ntziachristos, Curr. Mol. Med., $2004,4,419$.

908 W. Stöber, A. Fink, E. Bohn, J. Colloid Interface Sci., 1968, 26, 62.

9 A. Simoncsits, J. Tomasz, Nucleic Acids Res., 1975, 2, 1223.

10 See Figure S1 in the Supporting Information.

11 See Figure S3 in the Supporting Information.

12 Quantitative data are shown in Figure S4 in the Supporting Information.

13 A. Burns, H. Ow, U. Wiesner, Chem. Soc. Rev., 2006, 35, 1028. 